\title{
Apontamentos metodológicos e curriculares discentes para os cursos de pós-graduação em Escrita Criativa no Brasil
}

\author{
Alumni methodological and curricular notes for postgraduate courses \\ in Creative Writing in Brazil
}

\author{
LUIZ ANTONIO DE ASSIS BRASIL ${ }^{1}$ \\ BERNARDO BUENO ${ }^{1}$ \\ LUÍS ROBERTO DE SOUZA JÚNIOR ${ }^{2}$ \\ MOEMA VILELA PEREIRA ${ }^{2}$ \\ ÁNGElA MARÍA CUARTAS VILLALOBOS ${ }^{3}$ \\ DANIEL FERNANDO GRUBER ${ }^{3}$ \\ FELIPE KARPINSKI MASSARO ${ }^{3}$ \\ GABRIEL EDUARDO BORTULINI ${ }^{3}$ \\ GEYSIANE ANDRADE ${ }^{3}$ \\ HARINI ABJA KANESIRO 3 \\ JULIANA MAFFEIS ${ }^{3}$ \\ LARA MARIA LUFT ${ }^{3}$ \\ MARÍA ELENA MORÁN ATENCIO ${ }^{3}$ \\ TIAGO DANTAS GERMANO ${ }^{3}$ \\ VITORIA DE ALMEIDA FONSECA ${ }^{3}$ \\ Programa de Pós-Graduação em Letras da PUCRS. Porto Alegre, RS, Brasil. \\ ${ }^{2}$ Curso Superior de Tecnologia em Escrita Criativa da PUCRS. Porto Alegre, RS, Brasil. \\ ${ }_{3}^{3}$ Pontifícia Universidade Católica do Rio Grande do Sul. Porto Alegre, RS, Brasil.
}

Resumo: Este artigo analisa os resultados da segunda etapa da pesquisa Escrita criativa na Academia: a formação do escritor, desenvolvida desde 2015 no Programa de Pós-graduação em Letras (PPGL) PUCRS, cujo objetivo geral é verificar a estrutura curricular e as condições de ensino oferecidas pelos cursos de mestrado e doutorado voltados para a formação do escritor e do pesquisador na área de Escrita Criativa na universidade. Nesta etapa, procurou-se verificar qual a percepção dos discentes acerca das disciplinas oferecidas, bem como os procedimentos metodológicos adotados no curso, visando melhor adequação dessas propostas, bem como apontar caminhos para uma implantação ampla da Área da Escrita Criativa no Brasil.

Palavras-chave: Escrita Criativa; Ensino Superior; Pós-graduação; PUCRS; Brasil.

\begin{abstract}
This article analyses the results of the second stage of the research Creative Writing in Academia: the writer's education, developed since 2015 at the Pontifical Catholic University of Rio Grande do Sul (PUCRS) Graduate Program in Letters. The general objective is to verify the curricular structure and the teaching conditions offered by the Masters and Doctoral courses focusing on the education of writers and researchers in the area of Creative Writing at PUCRS. At this stage, we sought to ascertain the students' perceptions about the modules and methodological procedures adopted in the course, aiming at a better development of these proposals, as well as to point out ways for a wider implantation of Creative Writing in Brazil.
\end{abstract}

Keywords: Creative Writing; Higher Education; Graduate Studies; PUCRS; Brazil. 


\section{Introdução}

O presente artigo representa os resultados da continuidade da pesquisa $A$ escrita criativa na Academia: a formação do escritor, do Programa de Pós-graduação em Letras da Pontifícia Universidade Católica do Rio Grande do Sul (PUCRS). Aqui, discutem-se os resultados de um questionário que foi distribuído a discentes que frequentaram os cursos de mestrado e doutorado na área de concentração em Escrita Criativa na PUCRS até 2016. As perguntas tratavam das experiências e percepções dos discentes, e abriam espaço para observações em caráter aberto. Detalhes sobre o contexto, objetivos, metodologias e resultados parciais da pesquisa podem ser encontrados em ASSIS BRASIL et al. (2017). Uma maior contextualização da Escrita Criativa na PUCRS e reflexões sobre a representatividade dessa área no ensino superior brasileiro estão disponíveis em ASSIS BRASIL (2015).

O primeiro artigo com análises das respostas (mencionado acima) foi publicado em 2017. Dedicava-se a discutir os motivos que levaram os discentes a buscar uma formação de pós-graduação em Escrita Criativa e, além disso, a importância atribuída por eles a diferentes aspectos dessa formação, como o desenvolvimento da capacidade de leitura, o desenvolvimento da prática da escrita e a troca de experiências com os colegas, entre outros. Verificou-se que os alunos de mestrado em Escrita Criativa têm maior interesse em um curso de perfil dinâmico, que os ensine a ler e a escrever Literatura, e que lhes dê espaço para fazê-lo ao longo do curso, contando com orientação de professores especialistas e com experiência literária. No doutorado, entretanto, vemos outros aportes: seria um curso voltado para aqueles que, além de escrever, têm o objetivo de dar aulas, estudar a teoria de forma aprofundada, e desenvolver investigações na área da Escrita Criativa.

O presente artigo analisa aspectos diferenciados da mesma pesquisa, buscando um diálogo com os resultados anteriormente obtidos. Por um lado, analisaram-se as respostas sobre atividades específicas do curso, como disciplinas, cursos, eventos e metodologias de ensino; por outro, oferecem-se propostas para o melhor encaminhamento de cursos de pós-graduação em Escrita Criativa no Brasil. Espera-se que, assim, obtenha-se o registro da experiência discente em uma área ainda recente no país e contribua-se para seu contínuo desenvolvimento.

\section{Apontamentos discentes: uma análise adicional}

$\mathrm{O}$ atual estudo segue o modelo de análise do artigo anterior, interpretando as respostas às questões objetivas e subjetivas respondidas pelos alunos e ex-alunos entrevistados. Nesta primeira parte, a análise se concentra nas questões que se referem às atividades oferecidas pela PUCRS para a formação em Escrita Criativa, em níveis de relevância e expectativa. Os grupos de respondentes foram divididos da seguinte maneira (todos com sujeitos que cursaram pós-graduação na área em Escrita Criativa na PUCRS): Grupo 1, com 32 participantes, formado por discentes de mestrado e doutorado, cursados pela primeira vez e em andamento; Grupo 2, com 9 participantes, agrupando discentes com mestrado concluído e doutorado em andamento na mesma área; Grupo 3, com 28 participantes, juntava discentes com apenas mestrado concluído; enquanto o Grupo 4, com 3 participantes, era formado por ex-discentes com doutorado concluído na área.

A questão Para você, qual a relevância das seguintes atividades oferecidas pela PUCRS para a sua formação em Escrita Criativa? demonstra, no geral, um equilíbrio entre as respostas. No entanto, há algumas exceções, como é o caso do item Disciplinas oferecidas na área de Linguística que, para o Grupo 4, foi marcado como "Pouco relevante" em 66,7\% das respostas e como "Nada relevante" nos outros 33,3\%. Situação parecida à do Grupo 2, no qual 55,56\% dos participantes marcou a opção "Pouco Relevante" e outros 22,22\% marcaram a opção "Nada relevante". Esse foi o item com a menor média ponderada em todos os grupos, indicando que os discentes atribuem baixa relevância às disciplinas da área de Linguística.

Por outro lado, verificamos que a resposta ao item Disciplinas oferecidas na área de Escrita Criativa obteve a maior média ponderada em três dos quatro grupos pesquisados. Apenas o grupo 2 indicou maior relevância ao item Grupos de pesquisa. No entanto, Disciplinas oferecidas na área de Escrita Criativa foi apontado como "Muito relevante", a pontuação máxima, em 66,67\% das respostas. Já no Grupo 1, o item foi elencado como "Muito relevante" em 93,75\% dos casos; no Grupo 3, em $75 \%$, e em 100\% no Grupo 4.

A importância que os discentes atribuem às disciplinas voltadas à área da Escrita Criativa tem relação com a necessidade, apontada já no artigo anterior, de praticar a escrita. Em todos os grupos, há comentários recorrentes, no espaço para observações, que apontam a necessidade de disciplinas específicas de estudo e prática na área de Escrita Criativa. Também há apontamentos como "quantidade e variedade ainda é tímida", com referência às disciplinas práticas; e de como a ausência de disciplinas orientadas para a Escrita Criativa "é um obstáculo violento para a formação do pesquisador na área".

Nesse sentido, a oferta de disciplinas para o ano de 2018 vai ao encontro das solicitações dos discentes e tenta 
suprir a ausência de disciplinas voltadas à área da Escrita Criativa. ${ }^{1}$ No primeiro semestre, foram oferecidas três disciplinas específicas: "Oficina de Criação I: Narrativa"; "Curso: Textos Breves e Híbridos: Reflexão e Prática"; e "Seminário Livre de Escrita Criativa I". No segundo semestre, há uma oferta ainda maior. São seis disciplinas e, dentre elas, duas são seminários de cinco encontros: "Seminário de Escrita Criativa II" e "Seminário de Escrita Criativa III". As demais são: "Teorias da Criação Dramática", "Teorias da Criação Ficcional", "Oficina de Criação IV: Texto não Ficcional e Outras Linguagens", e, por último, "Literatura e Fotografia" - que deixou de ser um seminário de cinco encontros e passou a ser, em 2018, uma disciplina semestral.

Para que tais disciplinas fossem oferecidas, novos professores passaram a fazer parte do Programa de PósGraduação, visando a uma atuação maior de docentes com formação específica em Escrita Criativa e experiência. A consequente oferta de maior número de disciplinas específicas atende às sugestões e necessidades apontadas tanto nas questões objetivas quanto subjetivas do questionário, já que os entrevistados mencionaram, muitas vezes, a necessidade de um incremento de professores que fossem também escritores.

Outro levantamento recorrente nas sugestões dos entrevistados sobre a variedade de gêneros literários abordados nas disciplinas. Como tentativa de fornecer uma maior diversidade de gêneros estudados, em 2017 e 2018 foram oferecidas disciplinas que exploravam não ficção, o texto dramático e a relação da literatura com linguagens digitais. Nota-se, no entanto, a reivindicação frequente por mais disciplinas que se dediquem à criação poética. Para tanto, o PPGL selecionou um docenteescritor, voltado ao campo da poesia, para ocupar bolsa de pós-doutoramento PNPD. Esse movimento entre as percepções dos discentes e a oferta de disciplinas é constante e necessário, tendo em vista que a área de concentração em Escrita Criativa no PPGL da PUCRS existe apenas desde 2012.

Em relação ao item "Orientação", somente o Grupo 3 apresentou uma porcentagem de participantes que considerou a atividade "Pouco relevante": $3,57 \%$. No entanto, $50 \%$ dos participantes desse grupo marcaram a opção "Muito Relevante" e 46,43\%, a opção "Relevante". No Grupo 1, que, entre os quatro grupos, foi o que atribuiu maior relevância à orientação, essa opção foi considerada "Muito relevante" por 75\% dos participantes e "Relevante"

\footnotetext{
1 Os dados brutos da pesquisa, com suas respostas e observações, foram compartilhados com a Coordenação de Pós-graduação em Letras da PUCRS. Esse fato possibilitou o maior conhecimento acerca das percepções dos discentes, gerando, assim, novos índices para o planejamento da oferta de disciplinas, cursos, eventos e atividades na área de Escrita Criativa.
}

por 25\%. No Grupo 2 e no Grupo 4, verificou-se a mesma média ponderada, sendo que, em ambos os grupos, $33.33 \%$ dos participantes indicaram o item como "Muito relevante" e 66, 67\%, como "Relevante".

Nas respostas abertas, quatro participantes abordaram a questão da orientação: um do Grupo 2 e os demais do Grupo 1. O participante do Grupo 2 referiu-se elogiosamente à sua orientação, afirmando que estava tendo um bom acompanhamento pelo seu orientador. No Grupo 1, as críticas diziam respeito não à relevância da atividade, mas à sua qualidade na experiência particular a cada participante. Nos três casos, a orientação foi considerada incompleta, sendo que, em duas das respostas, foi apontada como problema a preterição da parte criativa em relação à parte teórica do trabalho final.

A orientação de trabalhos de Escrita Criativa requer certa adaptação por parte dos orientadores: o modelo da PUCRS divide o trabalho final entre ensaio e prática criativa, numa proporção aproximada de $30 \%$ e $70 \%$, respectivamente. A orientação deve dar conta tanto de um diálogo com a teoria literária (no ensaio) quando das exigências de edição, leitura crítica, desempenho no gênero escolhido e diálogo com a tradição literária, no elemento criativo.

O item "Grupos de pesquisa", a seu turno, foi mais diversamente avaliado pelos quatro grupos. No Grupo 1 e no Grupo 3, respectivamente, $3,13 \%$ e $3,57 \%$ dos participantes não atribuíram nenhuma relevância à atividade, opção que, notadamente, não foi marcada nos outros dois grupos. O Grupo 2 foi o que considerou os grupos de pesquisa mais relevantes, com $66,67 \%$ dos participantes apontando o item como "Muito Relevante" e 40, 63\%, como "Relevante".

Alguns entrevistados destacaram a necessidade de mais grupos de pesquisa voltados à criação literária. Hoje, o PPGL tem três grupos específicos: "A Escrita Criativa na Academia: a formação do escritor", "Cartografias narrativas em Língua Portuguesa: redes e enredos de subjetividade", e o "TECFIC: Grupo de Pesquisa em Tecnologia e Ficção".

Outro tópico, que se repetiu no decorrer das respostas abertas, foi o da banca avaliadora: os sujeitos mencionaram a dificuldade de composição da banca, muitas vezes por falta de escritores com formação acadêmica na área, e os critérios específicos sobre as quais a arguição da banca está pressuposta. A falta de uma tradição em Escrita Criativa na Academia brasileira gera certas dificuldades, uma vez que o trabalho final difere da dissertação tradicional em cursos de Letras. A banca precisa avaliar os trabalhos do ponto de vista do escritor, seguindo critérios de avaliação diferenciados.

Os entrevistados também ressaltaram a importância da banca - de qualificação ou final - em fornecer sugestões 
e correções que ajudam a clarificar as ideias apresentadas no ensaio e no texto criativo. Isso é particularmente importante já que, caso o projeto literário do discente em questão seja ambicioso - para publicação ou estudos aprofundados - a versão apresentada ao final do curso pode não ser a versão definitiva (de um romance, por exemplo). A banca, neste caso, ajuda a ver muitos pontos do trabalho que precisam amadurecer e mudar.

Os itens relacionados à oferta de atividades extracurriculares, como eventos literários, palestras, encontros com escritores, cursos de extensão e intercâmbios tiveram, em geral, resultados que sugerem uma relevância média a baixa. Dentre elas, os encontros com escritores (entrevistas, discussões e palestras) obtiveram a maior média ponderada. No entanto, uma porcentagem de participantes dos grupos 2 e 3 considerou esta atividade "Pouco relevante": 22,22\% e 14,29\%, respectivamente. Já nos grupos 1 e 4 , todos os participantes consideraram esta atividade "Relevante" ou "Muito relevante". No grupo 1 esta resposta teve um destaque, sendo que $71,88 \%$ dos participantes marcaram a opção "Muito relevante". Em todos os grupos, os encontros com escritores em palestras, discussões ou entrevistas revelaram uma média ponderada muito próxima daquela observada nos itens "Cursos ministrados por escritores" e "Oficinas literárias".

Tal resultado ressalta a importância dada pelos discentes à experiência em sala: o contato com professores, o conteúdo das aulas, oportunidades de compartilhar textos, atividades de escrita e as etapas obrigatórias dos cursos (projeto, banca de qualificação, banca final), indicando que este é o elemento principal da experiência acadêmica, em sua percepção.

Por outro lado, os cursos de extensão são as atividades adicionais ao corpo curricular da pós-graduação para as quais os participantes deram menor relevância, seguida de perto pelos eventos literários como festivais e saraus. Nos grupos 3 e 4, uma porcentagem dos participantes consideraram os cursos de extensão como atividades nada relevantes para sua formação, a saber: 10,71\% e 33,33\%, respectivamente. No grupo 2, a opção "Muito relevante" não foi marcada por nenhum participante em relação aos cursos de extensão.

No entanto, nas respostas abertas houve alguns comentários sobre a necessidade da abertura do Mestrado em Escrita Criativa para um diálogo com outras artes e com outras linguagens ou áreas do conhecimento, como psicologia, arte, história da arte e comunicação audiovisual ou digital. Também a respeito da interdisciplinaridade, alguns participantes sugeriram a diversificação das disciplinas da pós-graduação, não apenas tratando de outros gêneros literários, mas também propiciando uma intersecção com outras áreas e linguagens criativas, pois isso poderia significar uma preparação maior dos futuros profissionais, os quais aplicariam as habilidades adquiridas no curso em áreas de atuação que se valem da escrita criativa para fins específicos, indo além da formação de escritores, da literatura acadêmica ou do mercado editorial. Tal sugestão, apesar de interessante, revela-se desafiadora: abrir a área de atuação do curso poderia descaracterizá-lo. No entanto, considerando a variedade de linguagens e plataformas disponíveis atualmente, especialmente considerando o universo digital, é importante seguir pensando sobre as diferentes formas de manifestação da literatura e em como cursos de Escrita Criativa podem trabalhar essa intermidialidade.

A pesquisa como um todo e as respostas abertas dos participantes abordam o assunto da inserção no mercado de trabalho. Vale a pena relembrar brevemente quais são as motivações que, de acordo com a pesquisa, levaram os discentes a escolherem o curso de Escrita Criativa, assunto que foi aprofundado no primeiro artigo sobre a presente pesquisa, em 2017. Com exceção da resposta que compreende o desejo pelo aprimoramento do conhecimento como escritor(a), que surge com maior média ponderada em todos os grupos, as demais respostas oscilam entre os interesses dos entrevistados. As respostas à questão Quais motivos levaram você a escolher o curso de Escrita Criativa? apontam o maior interesse dos discentes, em 76,39\% dos casos, consiste em "Aprimorar meu trabalho como escritor(a)". Com 41,67\%, o segundo maior interesse consiste em "Lecionar em universidades na área de Escrita Criativa". O terceiro resultado mais relevante é intenção de "Realizar pesquisas na área de Escrita Criativa", com 37,50\% das respostas. Em quarto lugar $(29,17 \%)$, encontramos "Começar minha carreira como escritor(a)" e "Ministrar oficinas de criação literária” e, em quinta posição (11,11\%), está “Aprimorar meu trabalho como ministrante de oficina de criação literária".

Os grupos 1 e 2 mencionam seu interesse em lecionar em universidades na área de Escrita Criativa, seguido da intenção de obter uma titulação acadêmica em nível de pós-graduação. Já os grupos 3 e 4 apresentam a intenção de obter uma titulação acadêmica em nível de pós-graduação com média ponderada equilibrada, seguidos do interesse em realizar pesquisas na área de Escrita Criativa. Em quarta posição aparece a intenção dos discentes de iniciar seu trabalho como escritor(a); em quinta, realizar pesquisas na área de Escrita Criativa. O interesse que menos surge entre a demanda dos discentes seria ministrar oficinas de criação literária.

Há, portanto, uma coerência entre os principais motivos que levaram à maioria dos participantes a escolherem o curso de Escrita Criativa e as atividades oferecidas pela PUCRS que eles escolheram como 
mais relevantes sua formação: as oficinas literárias, os encontros com escritores e as disciplinas oferecidas na área de Escrita Criativa. Nesse sentido, um dos participantes questiona se o objetivo do curso propõe a formação de escritores ou de professores e, sugere que, caso a intenção seja a primeira, o curso deveria se "desacademizar" e evitar uma relação direta com as diretrizes da CAPES. Para isso, o mesmo participante propõe um mestrado voltado para formação de escritores, e um doutorado para formação de professores.

Essa é, possivelmente, a questão mais complexa que afeta um curso de pós-graduação em Escrita Criativa: como equilibrar as exigências de um programa de pósgraduação em Letras, que por sua vez está invariavelmente ligado às exigências do Ministério da Educação. Alguns programas, como o da universidade de Columbia, em Nova York, entendem que o mestrado deve ser o grau final para escritores (o curso está, inclusive, dentro do Departamento de Artes, não no de Inglês, como é mais comum). Por outro lado, a universidade de East Anglia (UEA) no Reino Unido, recentemente passou a oferecer um Master of Fine Arts, um mestrado mais longo em Escrita Criativa, de dois anos (geralmente o mestrado, ou MA, tem um ano), de maneira a oferecer uma experiência acadêmica mais completa, inclusive com oportunidades para os discentes oferecerem suas próprias oficinas e tutoriais de escrita. A questão do lugar da Escrita Criativa na Academia, e seus desafios, segue em discussão e experimentação, como será discutido na seção seguinte. ${ }^{2}$

\section{Proposições para a Área da Escrita Criativa no Brasil}

A presente pesquisa esteve direcionada, desde sua formulação, a fazer um diagnóstico do programa acadêmico do curso de Escrita Criativa da PUCRS que pudesse reverberar em propostas para o seu futuro aprimoramento.

Um dos principais pontos levantados pelos participantes da pesquisa diz respeito à conjunção entre o conhecimento teórico e a experiência prática. A maioria dos programas de Escrita Criativa pelo mundo sustentamse nessa forte aliança teórico-prática para a abordagem do exercício da produção e reflexão literária. Alguns têm maior ênfase na prática a partir das disciplinas, como é o caso da Universidade de Iowa (EUA), com união de leitura crítica e o desenvolvimento avançado das práticas de escrita; a Universidade do Texas em El Paso - UTEP

\footnotetext{
2 Há de se ressaltar que o equilíbrio entre ensaio e texto criativo, no mestrado e doutorado da PUCRS, é bastante flexível, tanto em termos de extensão quanto de gênero, estilo e temática. Se as exigências acadêmicas - disciplinas, bancas, publicações - continuam, há um grande número de possibilidades de criação e abordagens de estudo.
}

(EUA), com o curso bilíngue de Maestría en Creación Literaria, mesclando conteúdo da Teoria Literária com exercícios de produção de textos; e a Universidade de East Anglia $^{3}$ (Inglaterra), que alterna workshops com assessorias individuais frequentes no projeto criativo, oferecendo, como opcionais, módulos com conteúdo teórico e crítico. Outros, como o $\mathrm{PhD}$ oferecido pela Universidade de Denver (eles não oferecem mestrado; todos seus pós-graduandos são doutorandos), se define por seu caráter interdisciplinar e altamente teórico:

Nós oferecemos um ambiente para escritores que são leitores sérios e interdisciplinares. Acreditamos que escritores são enriquecidos por uma dieta pesada de grande literatura em conjunção com filosofia, história, teoria crítica e estética, antropologia, história da arte e a história da ciência. Ensinamos os estudantes a ler constantemente, pensar muito, mas apenas raramente colocar essa escrita e pensamento conscientemente na sua escrita. Em vez disso, acreditamos que é a mente por trás do trabalho que é alterada e vai, por sua vez, eventualmente alterar a escrita (UNIVERSITY OF DENVER, 2018). ${ }^{4}$

Como mencionado na primeira parte do presente artigo, no espaço dedicado a críticas e sugestões, participantes dos quatro grupos indicaram a necessidade de maior número de disciplinas, oficinas e cursos oferecidos por escritores e de um conteúdo curricular voltado para a Escrita Criativa em diálogo com outras áreas, não se restringindo apenas à área de Letras. Por outro lado, há um compromisso do programa de pós-graduação da PUCRS em "equipar" os discentes com conhecimentos gerais da área de Letras, já que o curso engloba um mestrado e doutorado na área e não apenas em Escrita Criativa. As atuais disciplinas teóricas estão desenhadas em torno da Teoria da Literatura, a fim de fornecer ferramentas para os discentes que virão a desempenhar trabalhos de docência, crítica e produção acadêmica. ${ }^{5}$

Há de se considerar o desafio imposto pela escassez de bibliografia em português. Com uma maior oferta de

\footnotetext{
UNIVERSITY OF EAST ANGLIA, 2018.

4 Tradução nossa. No original: "We offer an environment for writers who are also serious and cross-disciplinary readers. We believe writers are enriched by a heady diet of great literature in conjunction with philosophy, history, critical and aesthetic theory, anthropology, art history, and the history of science. We teach students to read constantly, think hard, but only rarely to self-consciously put that reading and thinking into their writing. Instead we believe it is the mind behind the work that is altered and will in turn eventually alter the writing."

5 O segundo semestre de 2018 marcou a primeira vez que a grade de disciplinas da área de concentração em Escrita Criativa da pós-graduação em Letras da PUCRS foi oferecidas separadamente da de Teoria da Literatura. Isso se dá pela quantidade maior de professores e da oferta maior de disciplinas específicas. Os discentes são encorajados, entretanto, a equilibrar seus estudos entre as disciplinas específicas e as teóricas da área de Teoria da Literatura (Como Teorias da Narrativa/ Drama/ Lírica).
} 
disciplinas específicas, há uma necessidade crescente de textos sobre a Escrita Criativa, sua pedagogia, suas oficinas, o funcionamento de orientações, seu papel na universidade, assim com manuais de escrita. Acredita-se que tal demanda pode ser atendida através de esforços de tradução e pesquisa no país.

Além de manter os espaços conquistados, é preciso refletir sobre as expectativas do discente aspirante a escritor ou a outras profissões relacionadas à escrita, cujas necessidades são distintas das dos discentes das áreas de Teoria da Literatura e Linguística. Um exemplo de programa com este tipo de desenho - planejado do início ao fim com o discente de Escrita Criativa em mente - é o mestrado em Escrita Criativa da Universidade Complutense de Madrid, na Espanha, ou a graduação em Escrita Criativa da PUCRS. ${ }^{6}$

A Universidade de Columbia também oferece o programa de escrita no nível de graduação e pósgraduação. O currículo é formado por workshops em vários gêneros atrelados a orientações individuais, que estimulam a produção criativa dos discentes durante todos os semestres, além de atividades, como palestras, seminários, peças e performances, com um intercâmbio entre artistas e escritores. A universidade ainda encoraja os discentes a realizarem disciplinas eletivas de outros programas oferecidos pela instituição: cinema, teatro e artes visuais.

Assim, da mesma forma que os estudos literários se abriram a novos conhecimentos de outras áreas do saber, a Escrita Criativa também deve avançar nesse sentido, como afirma Dawson (2005) em relação às universidades australianas:

[...] as universidades australianas demonstram que os programas de Escrita Criativa não têm que ser concebidos como uma anomalia institucional existente em esplêndido isolamento dentro da universidade pósmoderna. Escrita Criativa tem uma presença interdisciplinar na Austrália (DAWSON, 2005, p. 158). ${ }^{7}$

Os entrevistados apontam a necessidade de clarificar as etapas, orientações e objetivos de seu processo como

\footnotetext{
6 A graduação em Escrita Criativa da PUCRS é oferecida em nível superior tecnológico, com 5 semestres de duração e caráter interdisciplinar. O foco principal continua sendo a Literatura, mas os discentes passam por aulas de escrita narrativa, lírica e dramática, passando por não ficção e roteiro para games e linguagens digitais. $\mathrm{O}$ trabalho de conclusão de curso é, também, crítico-criativo, mas consideravelmente menor. Já o curso de Escrita Criativa do PPGL/PUCRS é um curso stricto sensu, ou seja, forma pesquisadores que poderão atuar como docentes em nível superior; o curso superior tecnológico não tem, precipuamente, esse objetivo.

7 Tradução nossa. No original: "Australian universities demonstrate that Creative Writing programs do not have to be conceived as an institutional anomaly existing in splendid isolation within the postmodern university. Creative Writing has an interdisciplinary presence in Australia".
}

discentes de Escrita Criativa. Os discentes precisam de uma percepção clara sobre o que é esperado deles, do grau de importância atribuído aos elementos teórico e criativo de seu trabalho e, principalmente, de um acompanhamento próximo, por parte dos orientadores, de sua produção literária, estabelecendo um diálogo enriquecedor e assertivo, no intuito de equilibrar a qualidade das orientações que os discentes recebem. Da mesma forma, algumas respostas apontaram que os professores externos, convidados a fazer parte das bancas de avaliação, deveriam oferecer um feedback o mais equilibrado possível, levando em consideração os dois componentes da obra, evitando assim que o peso da discussão recaia mais sobre um deles e desfavoreça o debate crítico do outro - em especial da parte criativa.

Neste quesito, a Universidade de East Anglia oferece um modelo muito interessante de assessoramento ou orientação em seu MFA, com um viés que eles chamam de "editorial":

O ensino do segundo ano segue o modelo do doutorado e abrange uma série de onze tutoriais individuais com o seu orientador para discutir seu trabalho em progresso. Esses encontros permitirão ao seu orientador fornecer um feedback editorial construtivo sobre seu trabalho em progresso e responder quaisquer perguntas que você possa ter. No semestre de outono você também passará por um programa de treinamento de professores, complementado por observações em sala de aula, e na primavera você terá a oportunidade de auxiliar no ensino do curso de graduação em Escrita Criativa. Incluindo oficinas, tutoriais e avaliações em dupla, seu trabalho será lido e comentado por membros do corpo docente aproximadamente 35 vezes ao longo do mestrado (UNIVERSITY OF EAST ANGLIA, 2018b). ${ }^{8}$

Portanto, é importante ressaltar que, tanto na East Anglia quanto na Columbia University ou na Universidade de Iowa, o foco maior é no trabalho final do discente, incentivado e acompanhado desde o primeiro semestre pelos professores orientadores. $\mathrm{O}$ discente recebe atenção individual, e todas as disciplinas e atividades extras são realizadas de acordo com os objetivos do trabalho,

\footnotetext{
8 Tradução nossa. No original: "The second year is taught on the model of the $\mathrm{PhD}$ and comprises a series of eleven individual tutorials with your supervisor to discuss your work in progress. These meetings will allow your supervisor to provide constructive editorial feedback on your work in progress and answer any questions you may have. In the autumn semester you will also follow a course of teaching training, supplemented by classroom observation, and in the spring you will be offered an opportunity to assist in the teaching of the undergraduate Creative Writing programme. Including workshops, tutorials and the double-marking of assignments, your work will be read and commented upon by faculty members around 35 times over the course of the MFA."
} 
esclarecidos e orientados desde o início do curso. Contudo, é preciso levar em conta também que a muitos programas internacionais possui estrutura independente e não são parte de uma área específica, como na PUCRS, onde Escrita Criativa é uma área de concentração do programa de Letras. Assim, todas as adaptações ainda devem condizer com o contexto onde o programa se enquadra.

É preciso estabelecer os objetivos do curso: formar escritores ou professores de escrita criativa? ${ }^{9}$ Para os entrevistados, se o objetivo for o primeiro, o curso de Escrita Criativa deve se "desacademizar um pouco". Logo, em se tratando de processo criativo e tendo a escrita como uma forma de arte, é preciso entender as especificidades que envolvem os processos de criação: uma compreensão que afeta a orientação, as bancas, as disciplinas, a coordenação e até o lugar do curso na própria universidade.

Criar é, basicamente, formar. É poder dar uma forma a algo novo. Em qualquer que seja o campo de atividade, nesse 'novo', de novas coerências que se estabelecem para a mente humana, fenômenos relacionados de modo novo e compreendidos em termos novos. $\mathrm{O}$ ato criador abrange, portanto, a capacidade de compreender; e esta, por sua vez, a de relacionar, ordenar, configurar, significar (OSTROWER, 2008, p. 9).

Assim, cada discente e professor tem maneiras diferentes de trabalhar, mas todos têm o objetivo de fazer algo inovador, autoral, sem automatismos ou engessamentos, que passe por um processo de transformação e aprendizado. É possível ensinar as técnicas de escrita, mas é necessário incentivar a imaginação e as habilidades do discente para que ele encontre sua própria linguagem e voz, e construir uma metodologia adequada de ensino, buscar conhecimentos de vários campos, propiciando um ambiente de liberdade $\mathrm{e}$ incentivo à criatividade. As novas formas de metodologias ativas de ensino talvez possam ser uma via para atingir esse caminho, no qual o discente é protagonista do processo de ensino-aprendizagem, com estrutura mais dinâmica, auxílio das novas tecnologias, explorando os conhecimentos de forma interativa e incentivando o diálogo entre os discentes.

De modo geral, a área acadêmica da Escrita Criativa começa a animar-se, e alguns resultados a longo e médio prazo podem ser antevistos. É preciso aprender e construir um diálogo com cada turma, com os modelos

\footnotetext{
9 É oportuno destacar que a pergunta, tal como formulada, poderia eventualmente levar à conclusão de que o um curso stricto sensu forma professores; como vimos, forma pesquisadores que poderão dedicar-se ao magistério superior. Não é demais lembrar que, para além disso, esses cursos não oferecem disciplinas pedagógicas.
}

internacionais e com os novos programas implantados a fim de vencer os desafios e consolidar essa área na universidade brasileira. Ressalta-se a importância desse diálogo nacional e internacional, para que a troca de experiências e o estabelecimento de parcerias estimule o crescimento e a transformação de cada curso. Espera-se que as informações colhidas através desta pesquisa contribuam para a expansão da área, refletindo sobre alguns aspectos da experiência discente e apresentando propostas para equilibrar as exigências da Academia com as necessidades da criação literária.

\section{Referências}

ASSIS BRASIL, Luiz Antonio de et al. Percepções e perspectivas discentes nos cursos de pós-graduação em Escrita Criativa da PUCRS. Navegações, Porto Alegre, v. 10, n. 2, p. 149-155, jul-dez. 2017.

ASSIS BRASIL, Luiz Antonio de. A escrita criativa e a universidade. Letras de Hoje, Porto Alegre, v. 50, n. esp. (supl.), p. 105-109, dez. 2015.

COLUMBIA UNIVERSITY. Columbia University School of the Arts Writing Program. Disponível em <https://arts.columbia. edu/writing $>$. Acesso em: 01 jul. 2018.

DAWSON, Paul. Creative writing and the new humanities. Londres e Nova York: Routledge, 2005.

OSTROWER, Fayga. Criatividade e processos de criação. 22 ed. Petrópolis: Vozes, 2008.

PhD in English-creative writing. University of Denver. Disponível em: <https:/www.du.edu/ahss/english/graduate/ creative-writing-phd/index.html>. Acesso em: 12 jul. 2018.

REVERA: Escritos de criação literária do Instituto Vera Cruz. São Paulo: Instituto Vera Cruz. Anual. ISSN 2526-4966. Disponível em: <http://site.veracruz.edu.br/instituto/revera/ index.php/revera>. Acesso em: 15 jun. 2018.

SCRIPTORIUM: Revista de escrita criativa do programa de Pós-graduação em Letras da PUCRS. Porto Alegre: EDIPUCRS. Semestral. ISSN 2526-8848. Disponível em: $<$ http://revistaseletronicas.pucrs.br/ojs/index.php/scriptorium>. Acesso em: 15 jun. 2018.

THE UNIVERSITY OF IOWA. College of Liberal Arts and Sciences: Writer's Workshop. Disponível em: <https:// writersworkshop.uiowa.edu/>. Acesso em: 01 jul. 2018.

UNIVERSIDAD COMPLUTENSE MADRID. Facultad de Ciencias de la Información: Máster Universitario - Escritura Creativa. Disponível em: <https:/www.ucm.es/data/cont/docs/ titulaciones/207.pdf>. Acesso em: 01 jul. 2018.

UNIVERSITY OF DENVER. University Writing Program. Disponível em: < https://www.du.edu/writing/> Acesso em: 01 jul. 2018.

UNIVERSITY OF EAST ANGLIA. Creative Writing. Disponível em: <https://www.uea.ac.uk/literature/creativewriting> . Acesso em: 01 jul. 2018. 


\section{Autores:}

LUIZ ANTONIO DE Assis BRASIL (correspondente)

Professor do Programa de Pós-Graduação em Letras da Pontifícia Universidade Católica do Rio Grande do Sul (PUCRS).

Porto Alegre, RS, Brasil.

laab@pucrs.br

BERNARDo BuENO

Professor do Programa de Pós-Graduação em Letras da Pontifícia Universidade Católica do Rio Grande do Sul (PUCRS).

Porto Alegre, RS, Brasil.

bernardo.bueno@pucrs.br

LUÍS ROBERTO DE SOUZA JÚNIOR

Professor do Curso Superior de Tecnologia em Escrita Criativa da Pontifícia Universidade Católica do Rio Grande do Sul (PUCRS). Porto Alegre, RS, Brasil.

luis.souza@pucrs.br
Moema Vilela Pereira

Professora do Curso Superior de Tecnologia em Escrita Criativa da Pontifícia Universidade Católica do Rio Grande do Sul (PUCRS).

Porto Alegre, RS, Brasil.

moema.pereira@pucrs.br

Ángela María Cuartas Villalobos, Daniel Fernando Gruber, FELIPE KARPINSKI MASSARO, GABRIEL EDUARDO BORTULINI, Geysiane ANDRADE, Harini ABJA Kanesiro Juliana MafFeIs, LaRa Maria Luft, María Elena Morán ATENCIO,

Tiago Dantas Germano, Vitoria de Almeida Fonseca

Pós-Graduandos de Letras, Curso Superior de Tecnologia em Escrita

Criativa da Pontifícia Universidade Católica do Rio Grande do Sul (PUCRS). Porto Alegre, RS, Brasil.

Recebido: $19 / 08 / 2018$

Aprovado: 19/08/2018 